to rheumatological disease and occurred after being hospitalized in intensive care unit.

Conclusion: The patients with inflammatory rheumatic diseases usually apply to the emergency department with urgent or less urgent clinical pictures. Rheumatoid arthritis, one of the most common inflammatory rheumatic diseases in almost all societies, was also the most common diagnosis in our study. In the vast majority of applications, infectious causes and disease activations related to immunosuppressive treatments were in the foreground. In addition, although vasculitis is the most common reason for the in-patients in clinical service, since the most frequent in-patients in intensive care unit and death is seen in the scleroderma group; caution should be exercised in the emergency applications of patients with these two groups.

References:

[1] Rheumatology consultation in the emergency department: Annual results. RAED 2014

Table. Examination of the diagnosis of $\mathbf{2 3 3}$ patients who were hospitalized and/or died from the emergency department

\begin{tabular}{lccc}
\hline \multicolumn{1}{c}{ Parameters } & $\begin{array}{c}\text { In-patients in clinical } \\
\text { service n, (\%) }\end{array}$ & $\begin{array}{c}\text { In-patients in intensive } \\
\text { care units n, (\%) }\end{array}$ & $\begin{array}{c}\text { Died patients } \\
\mathrm{n},(\%)\end{array}$ \\
\hline Vasculitis & $38(17.9)$ & $5(23.8)$ & $1(1)$ \\
Ankylosing spondylitis & $33(15.5)$ & $3(14.2)$ & $2(20)$ \\
Rheumatoid arthritis & $31(14.6)$ & $2(9.5)$ & $5(50)$ \\
Behcet's disease & $25(11.7)$ & $1(4.7)$ & \\
Systemic lupus erythematosus & $16(7.5)$ & $7(33.3)$ & \\
Scleroderma & $10(4.7)$ & & $1(10)$ \\
Antiphospholipid syndrome & $10(4.7)$ & & $1(10)$ \\
Psoriatic arthritis & $9(4.2)$ & $1(4.7)$ & \\
Family Mediterranean fever & $8(3.7)$ & $2(9.5)$ & \\
Sjogren's Syndrome & $8(3.7)$ & & \\
Still Disease & $7(3.3)$ & & \\
Gout & $7(3.3)$ & & \\
Undifferentiated connective tissue & $7(3.3)$ & & \\
disease & $3(1.4)$ & & \\
Dermatomyositis & $212(100)$ & & \\
Total & & & \\
&
\end{tabular}

Disclosure of Interests: None declared

DOI: 10.1136/annrheumdis-2020-eular.2938

\section{AB1157 1 SEASONAL INFLUENZA VACCINATION: KNOWLEDGE AND ATTITUDES IN RHEUMATIC PATIENTS}

G. Figueroa-Parra ${ }^{1}$, L. Santoyo-Fexas ${ }^{1}$, A. Moreno-Salinas ${ }^{1}$, C. M. GamboaAlonso $^{1}$, A. L. De-Leon-lbarra', D. Á. Galarza-Delgado', J. A. Esquivel Valerio'. ${ }^{1}$ Hospital Universitario “Dr. José Eleuterio González”, Servicio de Reumatología, Monterrey, Mexico

Background: Vaccines are one of the safest and effective public health interventions (1). Patients with rheumatic diseases (RD) have a higher risk of morbidity and mortality from vaccine-preventable infections (2). Seasonal Influenza vaccination (SIV) had shown to reduce the incidence, complications, admissions, and mortality from Influenza in patients with RD (3). Vaccine hesitancy is one of the threats to global health established by the $\mathrm{WHO}$.

Objectives: To assess the knowledge and attitudes of rheumatic patients about SIV.

Methods: A self-questionnaire was applied during a community speech for rheumatic patients in October 2019 and also was applied in the rheumatology clinic of the university hospital "Dr. Jose Eleuterio Gonzalez" in Monterrey, Mexico, between November and December 2019. The questionnaire asks age, rheumatic diagnosis, and ten questions. Results are shown in descriptive statistics, the Chisquare and Mann-Whitney $U$ tests were performed to compare groups. A P-value $\leq 0.05$ was considered statistically significant. Analyses were performed using SPSS version 22.0 .

Results: A total of 205 self-questionnaires were applied. $122(59.5 \%)$ in the community speech and $83(40.5 \%)$ in the clinic. The median age was 55 (45.75-62.25) years in the community population and $44(28-59)$ years in the clinic, also the diagnosis distribution was different (Table 1). Most patients considered that rheumatic patients can be vaccinated. About $80 \%$ of patients have ever been vaccinated for seasonal influenza. $87.7 \%$ and $77.1 \%$ considered that SIV is safe and effective. About $85 \%$ of patients considered SIV the best way to avoid complications of Influenza. About $40 \%$ considered not safe to be vaccinated for influenza and other vaccine at the same time. $23.8 \%$ and $48.2 \%$ considered that SIV weakens the immune system and renders it susceptible to infections. Most of the patients know that SIV is free. $23.0 \%$ and $42.2 \%$ consider other measures better than SIV. $17.2 \%$ and $33.7 \%$ considered that SIV will get them worse instead of helping them, and $9.0 \%$ and $14.5 \%$ think that his RD will get worst with SIV.

Table 1. Population Characteristics

\begin{tabular}{lccc}
\hline & $\begin{array}{c}\text { Community } \\
\mathrm{N}=95\end{array}$ & $\begin{array}{c}\text { Clinic } \\
\mathrm{N}=83\end{array}$ & $\mathrm{P}$ \\
\hline Age, years, median (IQR) & $55(45.75-62.25)$ & $44(28-59)$ & $0.001^{*}$ \\
Diagnosis, n (\%) & $67(70.5)$ & $46(55.4)$ & $0.037^{*}$ \\
-RA & $14(14.7)$ & $7(8.4)$ & 0.194 \\
-OA & $3(3.2)$ & $11(13.3)$ & $0.013^{*}$ \\
-SLE & $8(8.4)$ & $8(9.6)$ & 0.780 \\
-Other AID & $3(3.1)$ & $11(13.2)$ & $0.012^{*}$ \\
-Other NAID & & & \\
\hline
\end{tabular}

Conclusion: Misinformation about SIV is patent among rheumatic patients. It is a big challenge to clarify these myths to gain confidence about his safety and effectiveness and provide his benefits.

References:

[1] Hum Vaccin Immunother. 2013;9(8):1774-1778.

[2] Hum Vaccin Immunother. 2018;14(6):1311-1322.

[3] Ann Rheum Dis. 2020;79:39-52

Table 2. Questionnaire

\begin{tabular}{lccccc}
\hline & & Community & Clinic & P \\
& & $N=122(\%)$ & $N=83(\%)$ & \\
\hline 1. Can rheumatology patients be vaccinated? & Yes & $114(93.4)$ & $75(90.4)$ & 0.420 \\
& No & $8(6.6)$ & $8(9.6)$ & \\
2. Have you ever been vaccinated for Influenza? & Yes & $97(79.5)$ & $68(81.9)$ & 0.668 \\
& No & $25(20.5)$ & $15(18.1)$ & \\
3. Influenza vaccine is safe and effective: & Yes & $107(87.7)$ & $64(77.1)$ & $0.045^{*}$ \\
& No & $15(12.3)$ & $19(22.9)$ & \\
4. The best way to avoid compilations of influenza & Yes & $104(85.2)$ & $71(85.5)$ & 0.953 \\
is by using SIV: & No & $18(14.8)$ & $12(14.5)$ & \\
5. It is safe to be vaccinated for Influenza and & Yes & $73(59.8)$ & $48(57.8)$ & 0.774 \\
other vaccines at the same time: & No & $49(40.2)$ & $35(42.2)$ & \\
6. SIV weakens the immune system and renders & Yes & $29(23.8)$ & $40(48.2)$ & $<0.001^{*}$ \\
it susceptible to infections & No & $93(76.2)$ & $43(51.8)$ & \\
7. Do you know that SIV is freely provided? & Yes & $115(94.3)$ & $76(91.6)$ & 0.453 \\
& No & $7(5.7)$ & $7(8.4)$ & \\
8. Herbal medications, traditional medicine and & Yes & $28(23.0)$ & $35(42.2)$ & $0.003^{*}$ \\
some food (like orange) are better than SIV: & No & $94(77.0)$ & $48(57.8)$ & \\
9. SIV instead of helping me will get me worst: & Yes & $21(17.2)$ & $28(33.7)$ & $0.006^{*}$ \\
& No & $101(82.8)$ & $55(66.3)$ & \\
10. SIV will worst my rheumatic disease: & Yes & $11(9.0)$ & $12(14.5)$ & 0.226 \\
& No & $111(91.0)$ & $71(85.5)$ & \\
& & & & &
\end{tabular}

Disclosure of Interests: None declared

DOI: 10.1136/annrheumdis-2020-eular.5074

\section{AB1158 VACCINATION BARRIERS IN PATIENTS WITH RHEUMATIC DISEASES}

G. Figueroa-Parra ${ }^{1}$, A. Moreno-Salinas ${ }^{1}$, L. Santoyo-Fexas ${ }^{1}$, C. M. GamboaAlonso $^{1}$, A. L. De-Leon-lbarra', I. D. J. Hernandez-Galarza', D. Á. GalarzaDelgado', J. A. Esquivel Valerio'. ${ }^{1}$ Hospital Universitario "Dr. José Eleuterio González", Servicio de Reumatología, Monterrey, Mexico

Background: Patients with rheumatic diseases (RD) are at increased risk of infections, attributed to the underlying RD, comorbidities and immunosuppressive therapy, including glucocorticoids, disease-modifying antirheumatic drugs, etc. (1). While many infectious diseases can generally be prevented by vaccines, immunization rates in this specific patient population remain suboptimal (2). Despite being recognized as one of the most successful public health measures, vaccination is perceived as unsafe and unnecessary by a growing number of individuals. Lack of confidence in vaccines is now considered a threat to the success of vaccination programs (3).

Objectives: To describe the main causes of non-vaccination in patients with RD. Methods: A self-questionnaire was applied to a sample of patients with RD in the rheumatology clinic of the university hospital "Dr. Jose Eleuterio Gonzalez" in Monterrey, Mexico between September and December 2019. The questionnaire evaluated demographic characteristics (age, gender, diagnosis) and the vaccination status for Influenza (last year), pneumococcal (last 5 years), Herpes zoster (ever), Human papillomavirus (any dose) and Hepatitis B (any dose). It also includes a question asking: If you didn't receive any of the previous vaccines, what was the reason? (multiple-choice are shown in Table 2). Results are shown in frequencies and percentages. 